DOI: 10.1007/s11666-013-0042-5

1059-9630/\$19.00 ㄷ ASM International

\title{
Erratum to: Effect of Plasma Nitriding and Nitrocarburizing on HVOF-Sprayed Stainless Steel Coatings
}

Gayoung Park, Gyuyeol Bae, Kyungil Moon, and Changhee Lee

\section{Erratum to: Journal of Thermal Spray \\ Technology \\ DOI 10.1007/s11666-013-0035-4}

The author would like to add the acknowledgment listed below to the manuscript.

\section{Acknowledgments}

This work was supported by a grant from the National Research Foundation of Korea (NRF) funded by the Korean government (MEST) (No. 2011-0016724).

The online version of the original article can be found under doi:10.1007/s11666-013-0035-4.

Gayoung Park, Gyuyeol Bae, and Changhee Lee, Kinetic Spray Coating Laboratory, Division of Materials Science and Engineering, Hanyang University, Seoul 133-791, South Korea; and Kyungil Moon, Heat and Surface Technology Center, Incheon Technology Service Division for SMEs, Korea Institute of Industrial Technology, Incheon 406-840, South Korea. Contact e-mail: chlee@hanyang.ac.kr. 